\title{
Assessment of gap-filling interpolation methods for identifying mangrove trends at Segara Anakan in 2015 by using landsat 8 OLI and Proba-V
}

\author{
Sanjiwana Arjasakusuma, Abimanyu Putra Pratama, Intan Lestari \\ Department of Geographic Information Science, Faculty of Geography, Universitas Gadjah Mada, Indonesia
}

Received: 2019-11-23

Accapted: 2020-11-10

\section{Keywords:}

Interpolation;

Spatial-Downscaling NDVI;

Mann-Kendall;

Sens-slope

Correspondent email:

Sanjiwana.arjasakusuma@ugm.ac.id

\begin{abstract}
The monitoring of mangrove and its trend over large areas can be done using multi-temporal remote sensing technology. However, remote sensing data is often contaminated by cloud cover, and its corresponding shadow resulted in missing data. This study aims to assess the performance of the existed gapfilling techniques, such as, linear, spline, stineman, data interpolation Empirical Orthogonal Function (Dineof) and spatial downscaling strategy employing the Proba-V imagery in $100 \mathrm{~m}$, when being used for estimating the missing data and depicting the trend in NDVI from Landsat 8 OLI by using Mann-Kendall. The study was conducted in the Mangrove Forests at Segara Anakan, Central Java which threatened by climate change and human activities. Our result suggested that EOF-based interpolation gave better prediction results and more accurate in predicting longer missing data. Linear interpolation, on the other hand, was accurate to predict shorter missing data. Overall, all interpolation results can reconstruct 64 (spline) to $72 \%$ (Dineof) of missing data in NDVI with the RMSE of 0.10 (Dineof) - 0.13 (spline). A consistently decreasing trend was also found from the four interpolation methods, which showed the consistency of the interpolated values when used for deriving trends with similar patterns of overall decreasing trend and magnitude of changes of -0.0095 to -0.0099 (NDVI unit) over the mangrove areas in 2015. The result demonstrated the potential ability of gap-filling methods for simulating the value of missing data and for deriving trends.
\end{abstract}

(2020 by the authors. Licensee Indonesian Journal of Geography, Indonesia.

This article is an open access article distributed under the terms and conditions of the

Attribution(CC BY NC) licensehttps://creativecommons.org/licenses/by-nc/4.0/.

\section{Introduction}

Mangroves are one of the critical ecosystems that provide benefits both in terms of ecology and socioeconomic. Around the world, there are around $1.7 \times 10^{5} \mathrm{~km} 2$ of mangroves in a coastal environment (Valiela, Bowen, \& York, 2001). Although ecosystem services provided by mangroves are significant, the existing mangroves are threatened by the conversion of land use into non-mangroves such as ponds and other land use (Alongi, 2002). In addition to land conversion, mangroves are also threatened by the phenomenon of global warming with the rise of seawater (Gilman, Ellison, Duke, \& Field, 2008). Therefore, consistent monitoring of mangrove ecosystems on a regional scale is essential for tackling the possible impact of environmental deterioration on the mangrove ecosystem.

Indonesia is a country with the longest coastline in the world whose coastal areas can provide the environment for mangroves to sustain. One of the famous mangrove areas is Segara Anakan, in the southern part of Java Island. The mangrove ecosystem in Segara Anakan is located on a lagoon between the islands of Nusakambangan and the coast of Cilacap. Coastal ecosystems in the Segara Anakan area possess a high vegetation diversity, with 21 species of trees present in the coastal region (Hinrichs, Nordhaus, \& Geist, 2009). Over time, this ecosystem, including mangroves is threatened by changes in land use with the construction of settlements, fisheries, and agricultural areas (Ardli \& Wolff,
2009; Jennerjahn \& Yuwono, 2009; Yuwono et al., 2007). Therefore, anticipating the extent to which changes in land use affect the mangrove ecosystem needs to be done by using remote sensing technologies.

The development of remote sensing technology allows for multi-temporal observation by utilizing existing satellite image data archives. The campaign of optical remote sensing satellite with medium spatial resolution, such as Landsat that has been existed from 1970 with Landsat MSS mission, up to now Landsat 8 OLI (Roy et al., 2014) can be used for multitemporal observation. Landsat, in particular, has better spatial resolution $(30 \mathrm{~m})$ which is more suitable for mangrove monitoring than other coarser remote sensing data, for instance MODIS (Son et al., 2014). Several studies have employed this sensor for mangrove monitoring, especially for mapping mangrove extent and change detection (B. Chen et al., 2017; C.-F. Chen et al., 2013; Long \& Giri, 2011; Pham \& Yoshino, 2015; Son et al., 2014). However, big problem of optical satellite imagery such as Landsat is the persistent cloud cover especially in tropical areas (Weiss et al., 2014). The clouds and cloud shadow cover produced missing data on the imagery. To optimize the capabilities of Landsat imagery, especially in monitoring mangrove objects, digital image processing is needed to account for the missing data due to cloud cover.

Cloud cover is one main problem in the optical remote 
sensing system that renders objects under the coverage of cloud shadows to become undetected and resulted in missing data. The missing data can be reconstructed by using other data taken at different dates to perform a temporal interpolation, such as linear interpolation, as the simplest and straightforward method. However, linear interpolation analysis is working best only for short gaps and for variables that have high collinearity (Junninen, Niska, Tuppurainen, Ruuskanen, \& Kolehmainen, 2004). Therefore, other interpolation methods are available to accommodate the non -linear pattern that might happen by employing non-linear interpolation such as spline, stineman, and empirical orthogonal function. Those interpolation methods are essential to estimate the complete temporal profile of the remote sensing pixels, which are beneficial for environmental studies.

Remote sensing has the advantages in environmental applications, especially with the abundant availability of multi-temporal data on optical remote sensing. The spectral characteristics of optical remote sensing image data can reflect the biophysical characteristics of vegetation. However, classic problems in multi-temporal analysis using remote sensing of medium-scale optical systems are cloud cover resulted in the missing data. Gap-filling methods can be utilized for reconstructing the missing data, however, that temporal interpolation was commonly conducted in the coarse spatial resolution data $(>250 \mathrm{~m})$ and for atmospheric variables (Aires, Prigent, \& Rossow, 2004; Kilibarda et al., 2014; Lguensat, Tandeo, Fablet, \& Garello, 2014). Another approach to derive the missing data can be done by using the values from the coarser-resolution data which possesses higher temporal resolution than medium to high spatial resolution data, enabling better probability to acquire a cloud -free observation. The analysis can be done by implementing spatial downscaling analysis by modelling the relationships between coarse and medium to high spatial resolution pixels, to generate a higher spatial resolution data from the coarse resolution which can be used to replicate the missing values. The method of spatial downscaling was commonly used for climatic and atmospheric variables (C. Chen, Zhao, Duan, \& Qin, 2015; Fu, Xu, Zhang, \& Sun, 2018; Groppelli, Bocchiola, \& Rosso, 2011; Q. Zhang, Shi, Singh, Fan, \& Huang, 2017). Spatial downscaling method also can be combined with the geostatistical interpolation methods (X. Zhang, Jiang, Zhou, Xiao, \& Zhang, 2012). Therefore, it is imperative to test those methods to be implemented on medium spatial resolution remote sensing data, i.e. Landsat 8 OLI.

This study aims to assess the performance of interpolation methods in reconstructing the missing data to be able to be used for environmental monitoring applications, such as mapping the trend of greenness values (represented by using Normalized Difference Vegetation Index (NDVI) in this study) of important vegetation ecosystems i.e. Mangrove. The proper mapping method of the mangrove ecosystem was effectively performed by using optical remote sensing data (Aschbacher et al., 1995). In addition, mangrove ecosystem also requires a multi-temporal monitoring effort (Hartini, Saputro, \& Yulianto, 2010) due to the consistent and amplifying anthropogenic and climate change pressures. The mapping effort was better be conducted using data with high spectral and spatial resolution data (Ibharim, Mustapha, Lihan, \& Mazlan, 2015), such as Landsat system or other data with similar or higher spatial and spectral configuration, considering the typical narrow stands and small areas of mangroves (Green, Clark, Mumby, Edwards, \& Ellis, 1998). Based on the research gaps identified from the previous studies, research questions can be formulated into 2 (two) main questions, such as:

1. How accurate the temporal interpolation methods alone and when combined with the spatial downscaling methods for reconstructing the missing data of NDVI in medium spatial resolution imagery, for instance, Landsat

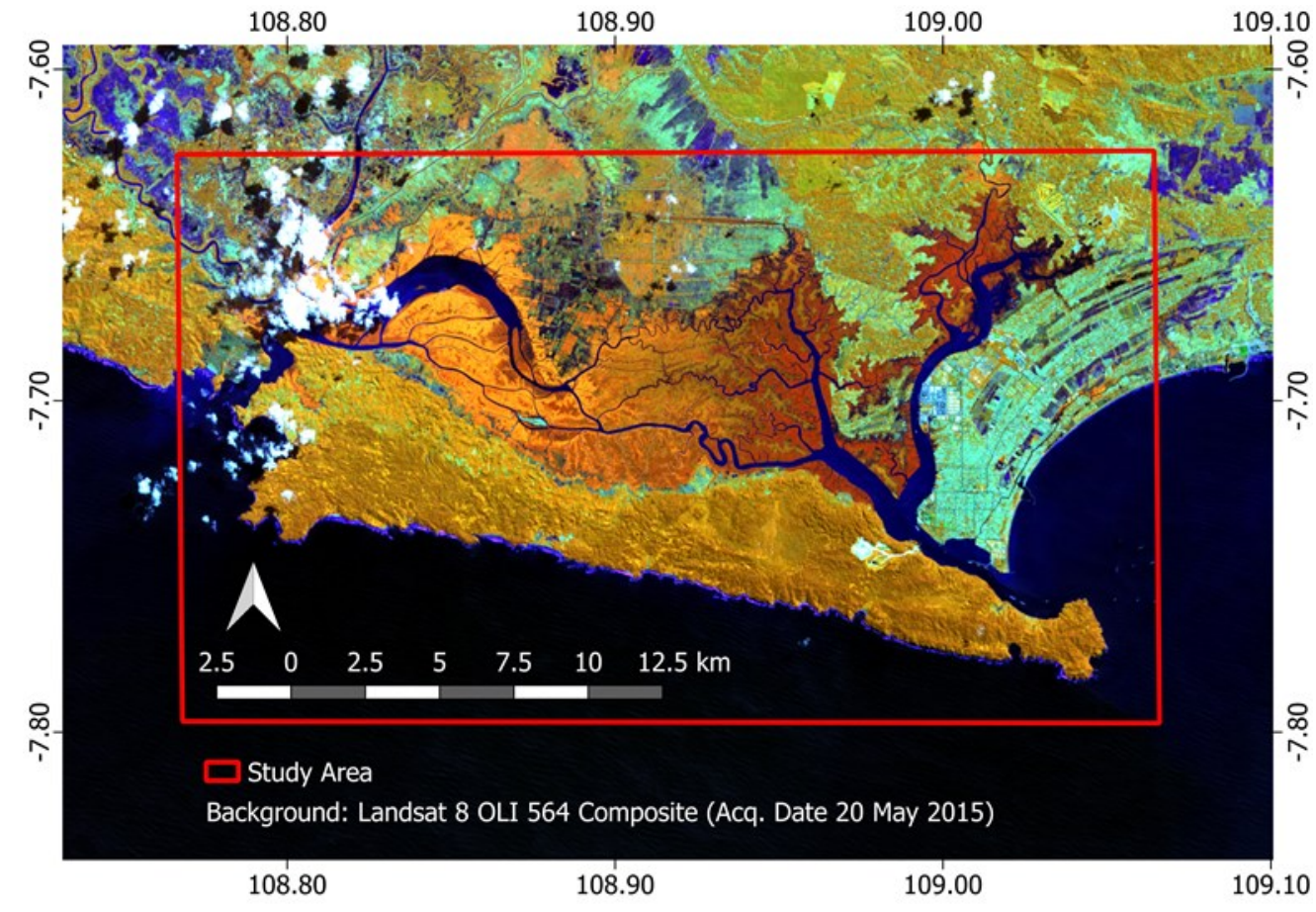

Figure 1. Map of the study area with land use information (source: author data analysis) 
8 OLI in Mangrove ecosystem, and

2. How consistent the resulted NDVI trends at Mangrove areas from different temporal interpolation methods

\section{The Methods}

\section{Study Area}

The study area is located at $108.73^{\circ}-109.19^{\circ} \mathrm{BT}$ and $7.87^{\circ}$ - $7.63^{\circ}$ LS, which is the area of Nusakambangan Island where the mangrove ecosystem of Segara Anakan is located (Figure 1). This area has quite diverse human activities, which are becoming the threats to mangrove ecosystem. The existence of an extensive sedimentation process due to unsustainable land-use change processes, through the Citanduy river resulted in sedimentation in the Segara Anakan lagoon by 2559 ha in 1978 - 2004 (Nordhaus, Hadipudjana, Janssen, \& Pamungkas, 2009). In addition to the Citanduy river, there are seven other rivers that have estuary channels in Segara Anakan (Holtermann, Burchard, \& Jennerjahn, 2009). If the process of changing land use on land is not adequately mitigated, the expansion of the sediment areas will affect the ecosystem of the mangrove in Segara Anakan.

Another threat is the land-use change in Segara Anakan which also triggers mangrove deforestation to change the function of land use in the area into farms and agricultural land and the existence of oil refineries located here because the waste from the oil refinery can damage the ecosystem in Segara Anakan (Nordhaus, 2009). The active human activities in this area encourage the importance of monitoring vegetation ecosystems, especially mangroves, which to sustain the ecological values of mangrove in Segara Anakan.

\section{Normalized Difference Vegetation Index (NDVI)}

Vegetation index is an image transformation that aims to highlight the appearance of vegetation in the image. This is done by performing a band ratio using channels on remote sensing images that are sensitive to vegetation, especially on near red and infrared channels. The most widely used vegetation index is the Normalized Differential Vegetation Index (NDVI) developed by Rouse, Haas, Schell, and Deering (1974), because of its easiness and high relationship to the greenness of vegetation and vegetation areas and its low sensitivity to topographic effects (Matsushita, Yang, Chen, Onda, \& Qiu, 2007).

The simplicity in NDVI calculations allows the provision of NDVI data over a long period. Some data providers provided NDVI from 1981 which was the beginning of the era of remote sensing. This data allows for more prolonged monitoring of the development and trend of vegetation. In this study, data NDVI from Landsat 8 OLI level 1 on path 121 and row 065 that have been corrected terrain, and the data of NDVI from Proba - V ESA with a spatial resolution of $100 \mathrm{~m}$ is used. Both of these data were chosen because of the high linear relationship between NDVI values generated by those data, especially in Southeast Asia (Arjasakusuma et al., 2018).

Landsat 8 OLI data were collected from January to December 2015 from USGS Earth Explorer with level-2 product or have been corrected into at-surface reflectance to match with the level of correction from Proba-V data. Clear pixels for each layer was then identified and cloud-and-cloud shadow contaminated pixels were removed by using the "pixel_qa" band and its corresponding code from Guide (2018), as reference. 12 (twelve) Landsat 8 imagery was used to represent the values in different months to match the period of the Proba- $\mathrm{V}$ data in the year 2015. Proba-V data is processed by using Maximum Value Composite (MVC) analysis (Equation 1.) to obtain maximum monthly value and reduce the effects of cloud disturbances.

$$
M V C=M A X \sum_{1}^{n} N D V I
$$

Where $\mathrm{n}=$ the number of scenes in the span of 1 month

\section{Interpolation methods}

Monitoring changes and trends in the earth's surface is usually done using multi-temporal data by utilizing the dense revisit time from remote sensing satellites. However, remote sensing satellites that have frequent (daily) revisit time are mostly remote sensing data with a coarse spatial resolution $(>100 \mathrm{~m})$. Higher spatial resolution data such as Landsat data do not have frequent revisit-time with remote sensing data with this rough resolution. Coupled with relatively high cloud frequencies in Indonesia, complete multi-temporal data with spatial resolutions such as Landsat become unavailable.

The gap-filling analysis aims to patch missing data mainly due to atmospheric disturbances or clouds. The commonly used method is to use linear interpolation by considering the trend of surrounding time-series values. But this method does not consider the variances that may occur frequently. Methods that accommodate variations in time series values that often occur can be done using the "empirical orthogonal function"(EOF) technique. This

Table 1. Interpolation methods explored in this study

\begin{tabular}{|c|c|c|}
\hline Interpolation Methods & Remote Sensing Data & References \\
\hline Linear Temporal Interpolation & & $\begin{array}{l}\text { An implementation of Spline from "rtsa" } \\
\text { package (Filipponi et al., 2018) }\end{array}$ \\
\hline Stineman Temporal Interpolation & $\begin{array}{c}\text { Landsat } 8 \text { OLI (12 Scenes from January to } \\
\text { December 2015) }\end{array}$ & $\begin{array}{l}\text { Stineman (1980) interpolation implement- } \\
\text { ed in "rtsa" package (Filipponi et al., 2018) }\end{array}$ \\
\hline Dineof Temporal Interpolation & & Alvera Azcarate et al. (2011) \\
\hline $\begin{array}{l}\text { (best accuracy temporal interpolation } \\
\text { (selected from the above method)) }+ \text { spa- } \\
\text { tial downscaling }\end{array}$ & Gap-filled Landsat 8 OLI + Proba-V data & $\begin{array}{l}\text { A combined methods constructed utilizing } \\
\text { Empirical Orthogonal Teleconnection } \\
\text { (Appelhans, Detsch, \& Nauss, 2015) and } \\
\text { temporal interpolation }\end{array}$ \\
\hline
\end{tabular}




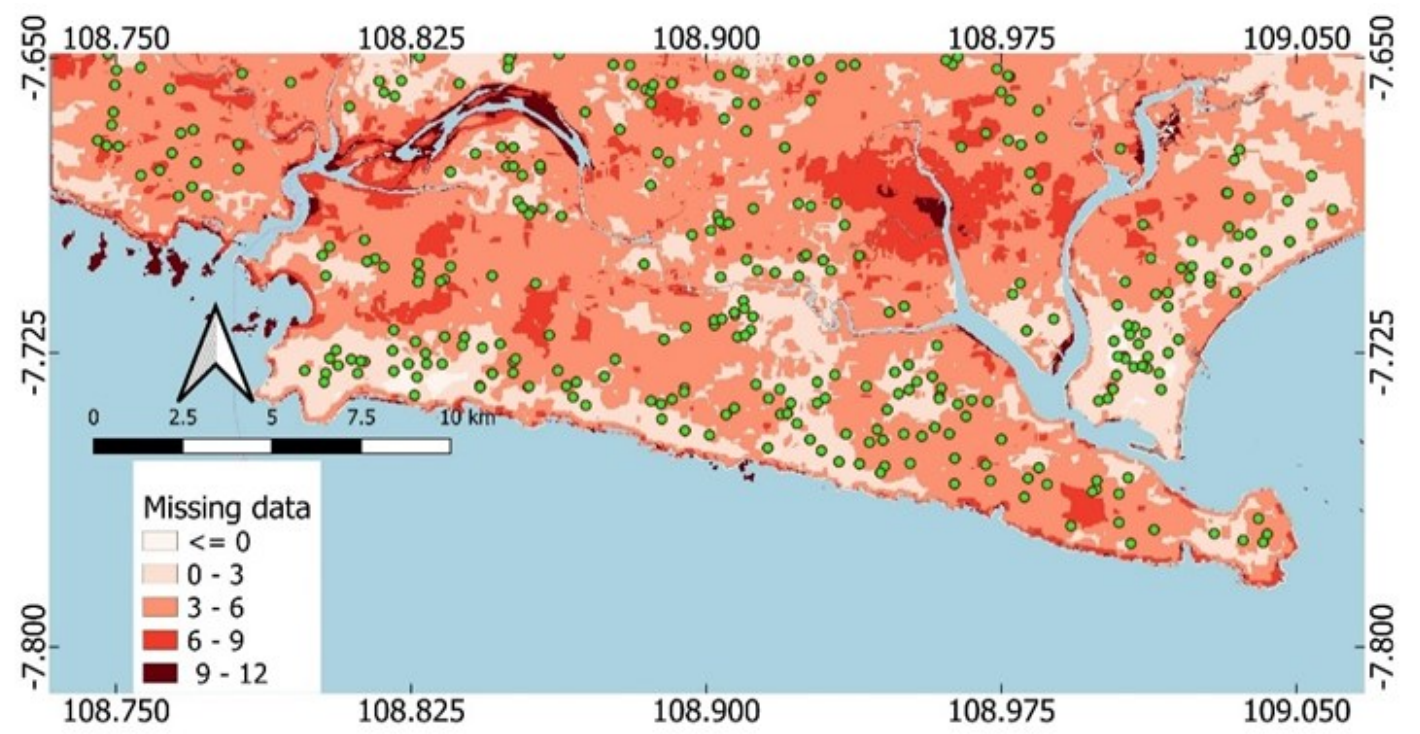

Figure 2. The number of missing data due to clouds and cloud shadows in the Landsat 8 OLI data in 2015. The green dots represent the validation points (360 data) (source: author data analysis)

algorithm uses the basic concept of principal component analysis (PCA), which collects modes that can explain most of the variance in the data. By patching gaps in time-series data, monitoring of multi-temporal remote sensing objects will be carried out. In this study, Data Interpolation Empirical Orthogonal Functions (DINEOF) data developed by Alvera Azcarate, Barth, Sirjacobs, Lenartz, and Beckers (2011) was tested and combined with linear, spline and stineman interpolation in filling in missing data in timeseries data. The spline is an interpolation method that applied a line fitting to match with the curve of the data while stineman interpolation, named after its inventor Stineman (1980), is also a curve-fitting method but can tolerate abrupt change in the data slope (Miller-Ihli, O'Haver, \& Harnly, 1984).

Besides employing the temporal values for interpolating the missing data, we developed an interpolation method that combined temporal interpolation and spatial downscaling methods. This method consists of 2 steps, 1.) performing temporal interpolation (selected from the best accuracy between, linear, spline, stineman and Dineof), and 2.) downscaling the Proba-V NDVI values $(100 \mathrm{~m})$ by using the gap-filled data as the reference for downscaling using the Empirical Orthogonal Methods. Therefore, there are five interpolation methods conducted in this study as mentioned in Table 1.

The analysis of gap-fill interpolation was conducted by using the "rtsa" package which had been developed and used by Filipponi et al. (2018) for filling the gap in MODIS data. While Empirical Orthogonal Teleconnection (EOT) method was conducted by using remote package (Appelhans et al., 2015)

\section{Validation}

Assessing the performance of the gap-filling techniques was conducted by sampling and removing the sample pixels from the data. We distributed randomly 30 points in each image layer (12 layers; the total of sample points was 360 points) at the areas which were not covered by clouds and cloud shadows. Afterward, we set the values in that point into NA or No Data. By performing the gap-filling techniques, the missing data were interpolated, and the results of the interpolation were compared with the original values. We further assessed the relationships between the number of missing data (gaps) with the prediction performance to conclude whether the interpolation is reasonable to predict only a short gap or can be used at longer gap of data. Quantitative assessment was conducted by calculating the $\mathrm{R}^{2}$ and RMSE.

Based on Figure 2., there are extensive clouds and cloud shadow coverage in the study area, with the range of missing data from 1 to 10 data from the total 12 data layers. Most of the study area was missing 3-6 data, which made this area suitable for the assessment of the gap-filling interpolation method.

\section{Trend Analysis in Mangrove Areas using Mann-Kendall dan Sens Slope}

Trend analysis is used to detect a downward trend or increase in the greenness values of mangroves in Segara Anakan. The trend analysis used are Mann-Kendall and Sens Slope. Mann-Kendall is used to detect the monotonic trend (increase or decrease) that occurs by looking at the Kendall's Tau value produced, while Sen's Slope is used to measure the magnitude of the trend that happens so that the amount of the decline is in accordance with the data unit. The MannKendall analysis is done using $\mathrm{R}$ with the "Kendall" package (McLeod, 2011) and Sens Slope Analysis using the package "Trend" (Pohlert, 2017).

Trend analysis was conducted by using the data which has been gap-filled by using the interpolation methods in 30$\mathrm{m}$ spatial resolution. The results of the analysis of trends in the gap-filled results were compared to assess whether different gap-filling techniques yielded a significantly different trend when the results were used in the trend analysis.

a. Landsat 8 which has gone through gap-filling processes with linear, spline, stineman and DINEOF interpolation, 


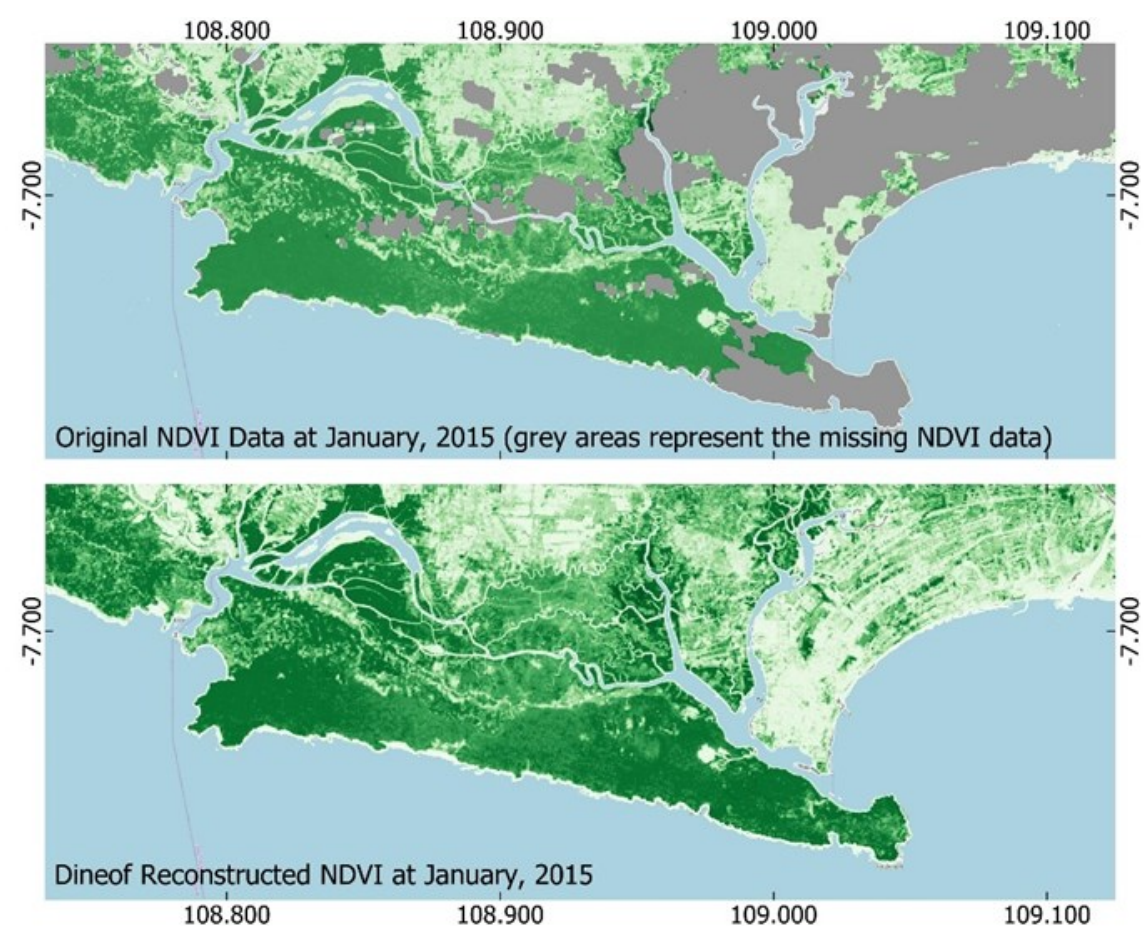

Figure 3. example of the NDVI reconstructed data in January 2015 (below) by using dineof interpolation which able to fill the values of missing data (source: author data analysis)
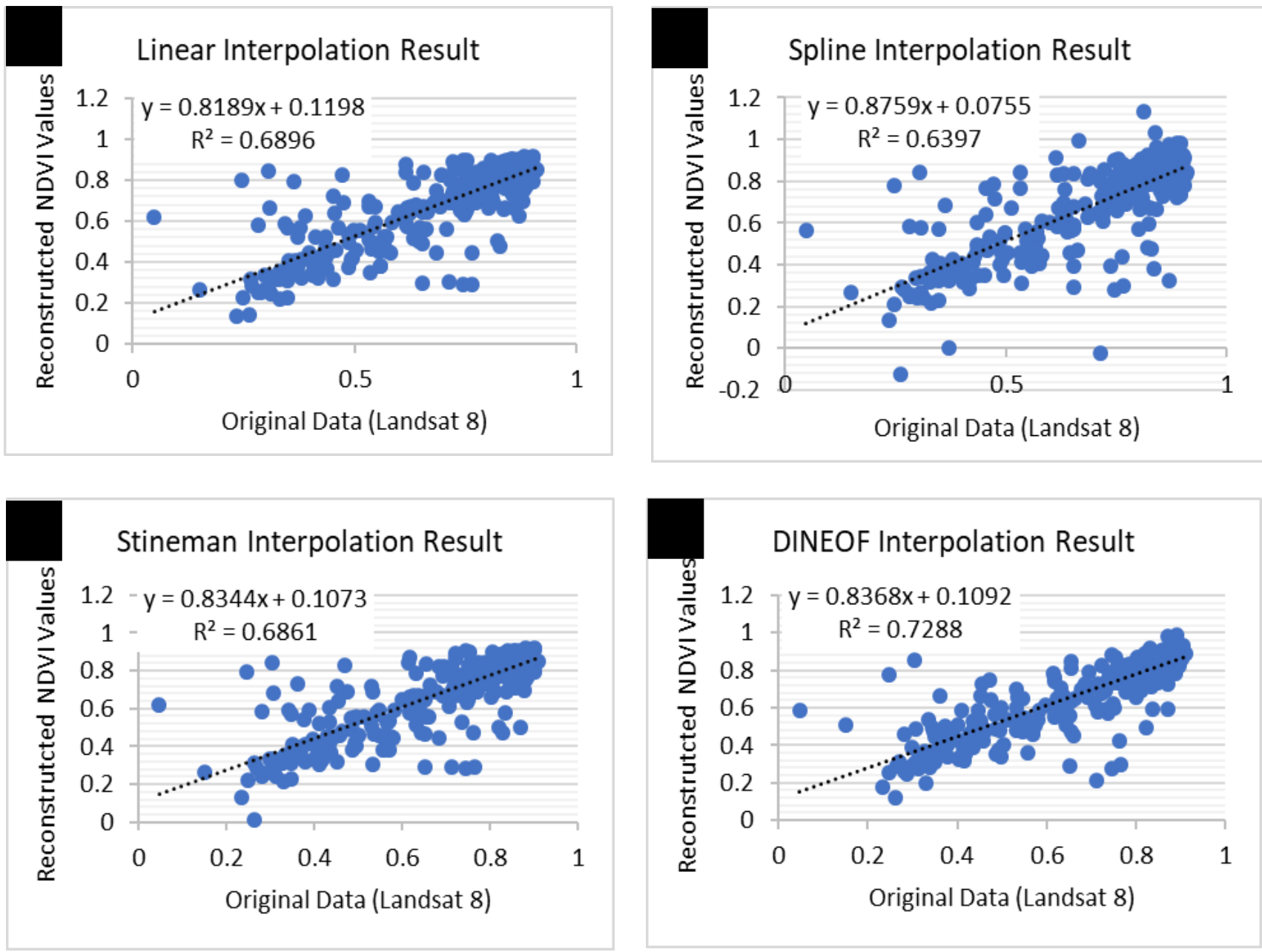

Figure 4. The validation results of the interpolated/reconstructed values (y-axis) versus the original NDVI values (x-axis) demonstrated Dineof as the best temporal interpolation method among other methods 
b. A downscaled Proba-v NDVI product by using the combination of empirical orthogonal function method and gap-filled Landsat 8 OLI (Dineof)

Mangrove data in this study were identified by using maximum likelihood classification by using spectral values of Landsat 8 OLI (single date data with relatively no clouds). The Landsat 8 data used for the classification was recorded on August 25, 2015. Majority filter (3 x 3 window size) and manual cleaning/refining by using visual inspection from Google Earth data for reference, were conducted to remove the misclassification from the result.

\section{Result and Discussion}

Interpolation and Validation Results

The interpolation produced the full coverage of the multitemporal data and has been able to successfully fill the missing data. An example of the results can be seen in Figure 3 where all the cloud-and-cloud shadows pixel were supplied by the interpolated values. The calculation will only apply to the pixels with the missing data. Therefore, the values of the non-missing data (identified as clear pixel in "qa_pixel" data) were unchanged. However, it can be seen in Figure 3 that the interpolation produced a nearly seamless image for single

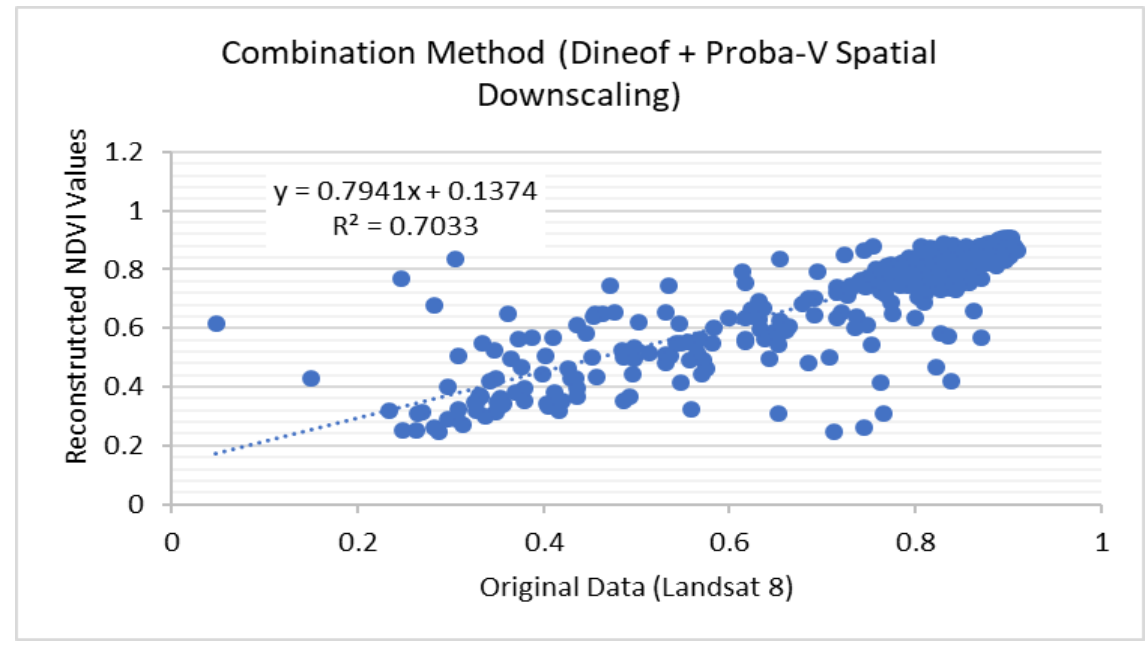

Figure 5. The performance of the combination method between spatial downscaling and temporal interpolation

(Source: Author data analysis, 2019)

Table 2. The performance of different gap-filling methods at different missing data scenarios (source: author data analysis, 2019)

\begin{tabular}{|c|c|c|c|c|c|c|c|}
\hline \multicolumn{2}{|c|}{$\begin{array}{c}\text { Accuracy at Different Number of } \\
\text { Gaps/Missing Data }\end{array}$} & RMSE & $\mathrm{RSq}$ & \multicolumn{2}{|c|}{$\begin{array}{c}\text { Accuracy at Different Number } \\
\text { of Gaps/Missing Data }\end{array}$} & RMSE & $\mathrm{RSq}$ \\
\hline \multirow{5}{*}{$\begin{array}{c}\text { Gap : } 1 \text { Data } \\
(\mathrm{n}=13)\end{array}$} & Linear & 0.165 & 0.676 & \multirow{5}{*}{$\begin{array}{c}\text { Gap : } 5 \text { Data } \\
(\mathrm{n}=92)\end{array}$} & Linear & 0.100 & 0.738 \\
\hline & Spline & 0.169 & 0.668 & & Spline & 0.125 & 0.667 \\
\hline & Stine & 0.166 & 0.678 & & Stine & 0.103 & 0.735 \\
\hline & Dineof & 0.168 & 0.656 & & Dineof & 0.102 & 0.723 \\
\hline & Downscaled EOF & 0.166 & 0.671 & & $\begin{array}{l}\text { Downscaled } \\
\text { EOF }\end{array}$ & 0.108 & 0.687 \\
\hline \multirow{5}{*}{$\begin{array}{c}\text { Gap : } 2 \text { Data } \\
(n=13)\end{array}$} & Linear & 0.156 & 0.651 & \multirow{5}{*}{$\begin{array}{l}\text { Gap : } 6 \text { Data } \\
\quad(n=69)\end{array}$} & Linear & 0.098 & 0.697 \\
\hline & Spline & 0.159 & 0.641 & & Spline & 0.109 & 0.669 \\
\hline & Stine & 0.157 & 0.648 & & Stine & 0.099 & 0.699 \\
\hline & Dineof & 0.162 & 0.670 & & Dineof & 0.075 & 0.819 \\
\hline & Downscaled EOF & 0.156 & 0.671 & & $\begin{array}{l}\text { Downscaled } \\
\text { EOF }\end{array}$ & 0.092 & 0.733 \\
\hline \multirow{5}{*}{$\begin{array}{c}\text { Gap : } 3 \text { Data } \\
(\mathrm{n}=40)\end{array}$} & Linear & 0.102 & 0.749 & \multirow{5}{*}{$\begin{array}{l}\text { Gap : } 7 \text { Data } \\
\quad(\mathrm{n}=44)\end{array}$} & Linear & 0.132 & 0.465 \\
\hline & Spline & 0.102 & 0.761 & & Spline & 0.161 & 0.360 \\
\hline & Stine & 0.101 & 0.758 & & Stine & 0.133 & 0.463 \\
\hline & Dineof & 0.082 & 0.826 & & Dineof & 0.135 & 0.437 \\
\hline & Downscaled EOF & 0.082 & 0.815 & & $\begin{array}{l}\text { Downscaled } \\
\text { EOF }\end{array}$ & 0.123 & 0.511 \\
\hline \multirow{5}{*}{$\begin{array}{c}\text { Gap : } 4 \text { Data } \\
(\mathrm{n}=80)\end{array}$} & Linear & 0.112 & 0.682 & \multirow{5}{*}{$\begin{array}{c}\text { Gap : 8-9 } \\
\text { Data }(n=10)\end{array}$} & Linear & 0.111 & 0.831 \\
\hline & Spline & 0.141 & 0.614 & & Spline & 0.072 & 0.894 \\
\hline & Stine & 0.117 & 0.668 & & Stine & 0.114 & 0.798 \\
\hline & Dineof & 0.099 & 0.755 & & Dineof & 0.049 & 0.946 \\
\hline & Downscaled EOF & 0.105 & 0.710 & & $\begin{array}{l}\text { Downscaled } \\
\text { EOF }\end{array}$ & 0.081 & 0.759 \\
\hline
\end{tabular}


imagery with no traceable artifact at individual data. However, the reliability of the interpolated values can only be assessed and examined from the validation result.

The validation results concluded that Dineof interpolation gave better accuracy when compared to linear, spline, and stineman interpolation. Dineof can simulate $72 \%$ of the missing data which is $3-8 \%$ higher than the other interpolation methods. In terms of RMSE, Dineof has the values of 0.104 while linear and stineman produced the RMSE values of 0.113 and 0.115 , while spline produced 0.131 of RMSE . The RMSE errors in the range of 0.104 to 0.131 , resembled around 5 to $6.5 \%$ deviation from the full range of NDVI values (-1 to 1$)$, while the RMSE difference between the interpolation methods yielded the range between 0.009 to 0.027 of NDVI unit. This validation concluded the superiority of Dineof when compared to the other methods. On the other hand, these results also demonstrated spline interpolation as the least suitable interpolation algorithm for reconstructing missing NDVI data due to the lowest accuracy and due to the calculation flexibility, can yield the values beyond the normal range of NDVI (see Fig. $4 \mathrm{~b}$ ). From the scatterplots in Figure 4, it can also be seen that spline produced the value above 1 for NDVI which were outside of the range of NDVI values. The other methods produced the interpolated values within the range of NDVI values from -1 to 1 . The error in spline interpolation can be provided by the nature of the curve-fitting calculation of spline which may produce overly high or low values when more missing data are existed. Our validation analysis concluded that Dineof as the best temporal interpolation algorithm which gap-filled

Table 3. Statistics of Mann-Kendall test and Sens Slope test at Mangrove Area in 2015

\begin{tabular}{|c|c|c|c|c|c|c|c|c|}
\hline \multirow[b]{2}{*}{ Trend Statistics } & \multicolumn{2}{|c|}{ Linear } & \multicolumn{2}{|c|}{ Spline } & \multicolumn{2}{|c|}{ Stineman } & \multicolumn{2}{|c|}{ Dineof } \\
\hline & $\begin{array}{c}\text { Kendall's } \\
\text { Tau }\end{array}$ & $\begin{array}{l}\text { Sens } \\
\text { Slope }\end{array}$ & $\begin{array}{c}\text { Kendall's } \\
\text { Tau }\end{array}$ & $\begin{array}{l}\text { Sens } \\
\text { Slope }\end{array}$ & $\begin{array}{c}\text { Kendall's } \\
\text { Tau }\end{array}$ & $\begin{array}{c}\text { Sens } \\
\text { Slope }\end{array}$ & $\begin{array}{c}\text { Kendall's } \\
\text { Tau }\end{array}$ & $\begin{array}{l}\text { Sens } \\
\text { Slope }\end{array}$ \\
\hline $\min$ & -1.0000 & -0.0874 & -1.0000 & -0.0785 & -1.0000 & -0.0880 & -0.9394 & -0.0538 \\
\hline mean & -0.4513 & -0.0096 & -0.3897 & -0.0099 & -0.4489 & -0.0098 & -0.4182 & -0.0095 \\
\hline $\max$ & 1.0000 & 0.0682 & 1.0000 & 0.1127 & 1.0000 & 0.0676 & 0.7273 & 0.0593 \\
\hline std deviation & 0.2734 & 0.0080 & 0.2509 & 0.0087 & 0.2634 & 0.0078 & 0.1990 & 0.0060 \\
\hline
\end{tabular}
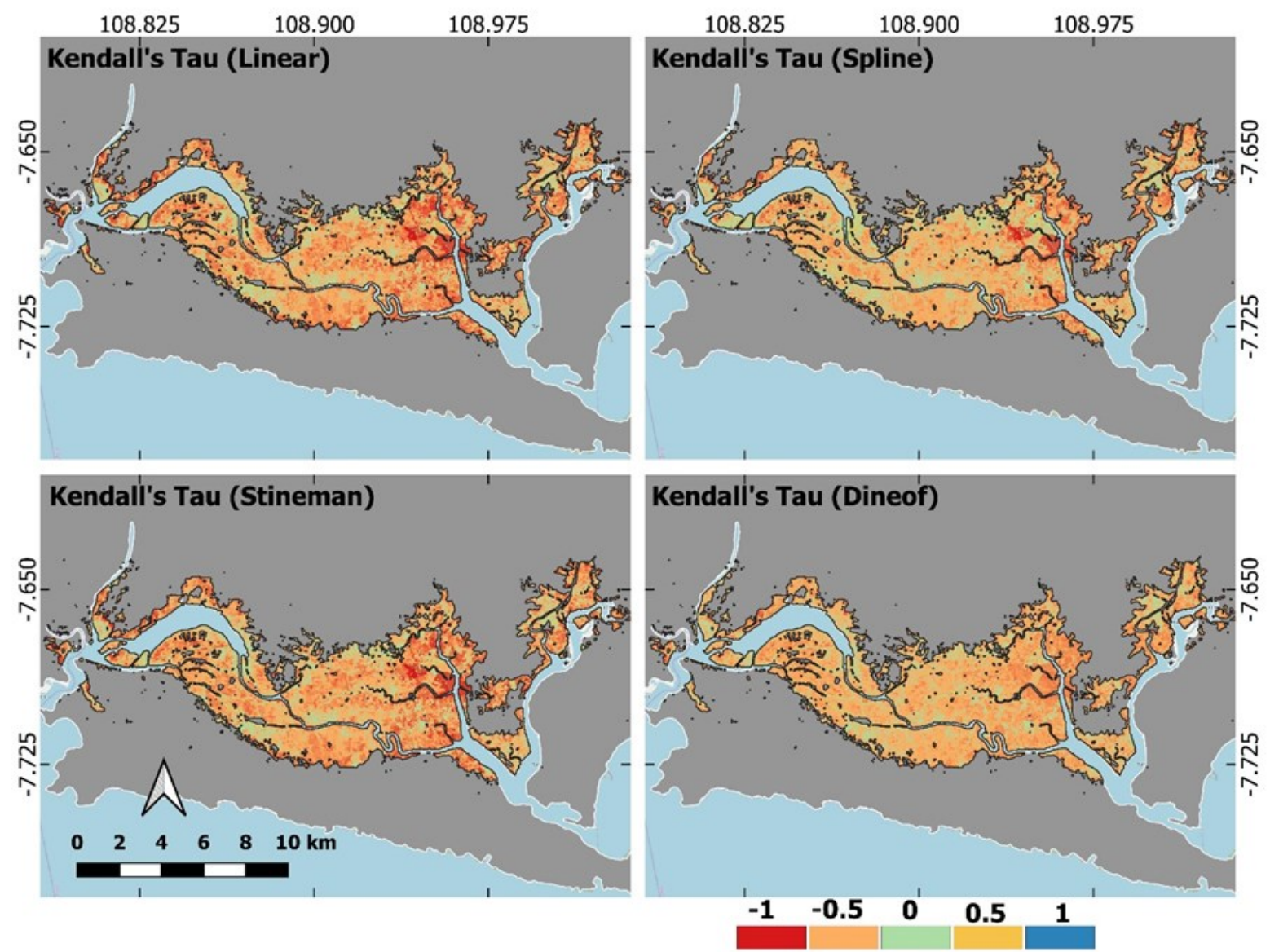

Figure 6. Comparison of Kendall's Tau values in mangrove region from different interpolation methods in which reddish color represents decreasing trend (closer to -1) and yellowish to blue represents increasing trend (closer to 1)

(Source: Author data analysis, 2019) 
data was used as the reference for conducting the downscaling process from Proba-V imagery.

The exploration of refining the gap-filled method by combining spatial downscaling from Proba- $\mathrm{V}$ data with Dineof interpolation results generated a lower accuracy when compared by the original Dineof data. The accuracy of the combination method between temporal interpolation (Dineof) and spatial downscaling (Proba- $\mathrm{V}$ with EOF) yielded an rsq of 0.703 and RMSE of 0.108 (Figure 5.), around $3 \%$ lower than the original Dineof interpolation. Further exploration should be made to explore which statistical properties showed a better relationship with Landsat 8. Here in this study, Maximum Value Composite was employed with the assumption that the cloud effects have been reduced. However, other statistical properties such as median or mean may give a better prediction result in the downscaling process since a recent study by Taddeo, Dronova, and Depsky (2019) suggested that median values from time-series data are more strongly related to the vegetation biophysical properties.

Although the overall results of the combined methods were lower than the Dineof interpolation, there was an increase in the prediction level in the event of 7 (seven) missing data (out of 12 data) where spatial downscaled eof produced the highest accuracy (Table. 2). Unfortunately, the increase is not consistent, and the performance in the other scenarios are notably lower than the original Dineof. From Table 2., It can be seen that the linear interpolation worked best at predicting short gaps such as missing 1-2 data and also at missing 5 data (5 gaps) while Dineof and downscaled eof worked best at predicting other numbers of missing data. Our results are also in conjunction with the result from Junninen et al. (2004), which suggested that linear interpolation performed best when predicting short gaps in missing data. For more missing data, our study revealed that dineof and downscaled dineof method performed better than the other methods. Limitation of dineof and downscaled dineof may lies on the longer computing time, especially when long time series data was used.

\section{The trend at Mangrove Areas in 2015}

The analysis of trends and magnitude from by performing the Mann-Kendall and Sens Slope test generated a similar overall pattern of trend. To acquire the trend over mangrove areas, the previous gap-filled results were cropped by using the mangrove map detected by using maximum likelihood, which has been refined by using majority filter and visual cleaning. In the mangrove areas, all interpolation results identified an averagely decreasing trend with Kendall's tau value of -0.42 to -0.45 and the magnitude of change from 0.0095 to -0.0099 of unit NDVI (Table 3.). Those statistics emphasized the overall decreasing trend over the mangrove areas in Segara Anakan in 2015. The highest degree of decrease was located in the east part of the mangrove areas which may be caused by the land-use change and/or sedimentation for the terrestrial areas (Figure 6.). Also, the decrease can be caused by the fact that the year 2015 is the ENSO (warm) active period, which affects mangrove in the area. However, finding the driving factor of the decreasing trend was not included in the scope of this study.

\section{Conclusion}

This study concluded the potential of the gap-filled method for reconstructing the missing data due to clouds and cloud shadows in the optical data by employing the temporal information from different dates and including the other NDVI data, supposedly from higher temporal resolution data through spatial downscaling. Dineof demonstrated a better prediction ability among the other methods for longer missing data while linear interpolation can be used for interpolating a short gaps in time series data, with spline as the least reliable method. The combination of spatial downscaling (EOT) of the Proba-V and a gap-filled data from Landsat (Dineof) produced a slightly lower accuracy than the original Dineof. As for trend analysis, it was found that the variety of gap-filling methods yield a relatively similar trend results both in the detection of the monotonic trend and the magnitude of changes. In our study areas, consistent decreasing trend with the magnitude of 0.0095 to -0.0099 (NDVI unit) was found at the Segara Anakan mangrove area in the year of 2015. The declining trends in Mangrove at Segara Anakan may be resulted from the strong ENSO event which happened on that year and created prolonged drought. However, further study can explore the reason for the decreasing trend of mangrove in Segara Anakan for planning future mitigation process. In addition, more exploration on the ability of temporal interpolation when identifying sudden change also should be conducted in the future study.

\section{Acknowledgement}

The author would like to thank the anonymous reviewer for the constructive comments made to the manuscript. This research was supported by the Research Grant for the Lecturer from Faculty of Geography.

\section{References}

Aires, F., Prigent, C., \& Rossow, W. (2004). Temporal interpolation of global surface skin temperature diurnal cycle over land under clear and cloudy conditions. Journal of Geophysical Research: Atmospheres, 109(D4).

Alongi, D. M. (2002). Present state and future of the world's mangrove forests. Environmental conservation, 29(3), 331 -349 .

Alvera Azcarate, A., Barth, A., Sirjacobs, D., Lenartz, F., \& Beckers, J.-M. (2011). Data Interpolating Empirical Orthogonal Functions (DINEOF): a tool for geophysical data analyses. Mediterranean Marine Science, 12(3), 5-11.

Appelhans, T., Detsch, F., \& Nauss, T. (2015). Remote: empirical orthogonal teleconnections in R. J. Stat. Softw, 65(10), 19.

Ardli, E. R., \& Wolff, M. (2009). Land use and land cover change affecting habitat distribution in the Segara Anakan lagoon, Java, Indonesia. Regional Environmental Change, 9(4), 235.

Arjasakusuma, S., Yamaguchi, Y., Nakaji, T., Kosugi, Y., Shamsuddin, S.-A., \& Lion, M. (2018). Assessment of values and trends in coarse spatial resolution NDVI datasets in Southeast Asia landscapes. European Journal of Remote Sensing, 51(1), 863-877.

Aschbacher, J., Tiangco, P., Giri, C., Ofren, R., Paudyal, D., \& Ang, Y. (1995). Comparison of different sensors and analysis techniques for tropical mangrove forest mapping. Paper presented at the 1995 International Geoscience and Remote Sensing Symposium, IGARSS'95. Quantitative Remote Sensing for Science and Applications. 
Chen, B., Xiao, X., Li, X., Pan, L., Doughty, R., Ma, J., . . . Wu, Z. (2017). A mangrove forest map of China in 2015: Analysis of time series Landsat 7/8 and Sentinel-1A imagery in Google Earth Engine cloud computing platform. ISPRS Journal of Photogrammetry and Remote Sensing, 131, 104120.

Chen, C.-F., Son, N.-T., Chang, N.-B., Chen, C.-R., Chang, L.-Y., Valdez, M., . . . Aceituno, J. L. (2013). Multi-decadal mangrove forest change detection and prediction in Honduras, Central America, with Landsat imagery and a Markov chain model. Remote Sensing, 5(12), 6408-6426.

Chen, C., Zhao, S., Duan, Z., \& Qin, Z. (2015). An improved spatial downscaling procedure for TRMM 3B43 precipitation product using geographically weighted regression. IEEE Journal of Selected Topics in Applied Earth Observations, 8 (9), 4592-4604.

Filipponi, F., Valentini, E., Nguyen Xuan, A., Guerra, C. A., Wolf, F., Andrzejak, M., \& Taramelli, A. (2018). Global MODIS Fraction of Green Vegetation Cover for Monitoring Abrupt and Gradual Vegetation Changes. Remote Sensing, 10(4), 653.

Fu, Y., Xu, S., Zhang, C., \& Sun, Y. (2018). Spatial downscaling of MODIS Chlorophyll-a using Landsat 8 images for complex coastal water monitoring. Estuarine, Coastal \& Shelf Science, 209, 149-159.

Gilman, E. L., Ellison, J., Duke, N. C., \& Field, C. (2008). Threats to mangroves from climate change and adaptation options: a review. Journal of Aquatic Botany, 89(2), 237-250.

Green, E., Clark, C., Mumby, P., Edwards, A., \& Ellis, A. (1998). Remote sensing techniques for mangrove mapping. International Journal of Remote Sensing, 19(5), 935-956.

Groppelli, B., Bocchiola, D., \& Rosso, R. (2011). Spatial downscaling of precipitation from GCMs for climate change projections using random cascades: a case study in Italy. Water Resources Research, 47(3).

Guide, P. J. A. o. h. 1. u. g. s. d. f. d. 1. p. g. p. (2018). Landsat 8 surface reflectance code (LaSRC) product.

Hartini, S., Saputro, G. B., \& Yulianto, M. (2010). Assessing the used of remotely sensed data for mapping mangroves Indonesia. Paper presented at the Selected topic in Power Systems and remote Sensing in 6th WSEAS International Conference on Remore Sensing (Remote'10), Iwate Prefectural University, Japan.

Hinrichs, S., Nordhaus, I., \& Geist, S. J. (2009). Status, diversity and distribution patterns of mangrove vegetation in the Segara Anakan lagoon, Java, Indonesia. Regional Environmental Change, 9(4), 275.

Holtermann, P., Burchard, H., \& Jennerjahn, T. (2009). Hydrodynamics of the Segara Anakan lagoon. Regional Environmental Change, 9(4), 245-258.

Ibharim, N., Mustapha, M. A., Lihan, T., \& Mazlan, A. (2015). Mapping mangrove changes in the Matang Mangrove Forest using multi temporal satellite imageries. Ocean and Coastal Management, 114, 64-76.

Jennerjahn, T. C., \& Yuwono, E. (2009). Segara Anakan, Java, Indonesia, a mangrove-fringed coastal lagoon affected by human activities. In: Springer.

Junninen, H., Niska, H., Tuppurainen, K., Ruuskanen, J., \& Kolehmainen, M. J. A. E. (2004). Methods for imputation of missing values in air quality data sets. Journal of Atmospheric Environment, 38(18), 2895-2907.

Kilibarda, M., Hengl, T., Heuvelink, G. B., Gräler, B., Pebesma, E., Perčec Tadić, M., \& Bajat, B. (2014). Spatio-temporal interpolation of daily temperatures for global land areas at $1 \mathrm{~km}$ resolution. Journal of Geophysical Research: Atmospheres, 119(5), 2294-2313.

Lguensat, R., Tandeo, P., Fablet, R., \& Garello, R. (2014). Spatiotemporal interpolation of Sea Surface Temperature using high resolution remote sensing data. Paper presented at the 2014 Oceans-St. John's.
Long, J. B., \& Giri, C. (2011). Mapping the Philippines' mangrove forests using Landsat imagery. Sensors, 11(3), 2972-2981.

Matsushita, B., Yang, W., Chen, J., Onda, Y., \& Qiu, G. (2007). Sensitivity of the enhanced vegetation index (EVI) and normalized difference vegetation index (NDVI) to topographic effects: a case study in high-density cypress forest. Sensors, 7(11), 2636-2651.

McLeod, A. (2011). Kendall-package: Kendall correlation and trend tests. $R$ package version, 2.

Miller-Ihli, N., O'Haver, T., \& Harnly, J. (1984). Calibration and curve fitting for extended range AAS. Spectrochimica Acta Part B: Atomic Spectroscopy, 39(12), 1603-1614.

Nordhaus, I., Hadipudjana, F. A., Janssen, R., \& Pamungkas, J. J. R. E. C. (2009). Spatio-temporal variation of macrobenthic communities in the mangrove-fringed Segara Anakan lagoon, Indonesia, affected by anthropogenic activities. Regional Environmental Change, 9(4), 291-313.

Pham, T. D., \& Yoshino, K. (2015). Mangrove mapping and change detection using multi-temporal Landsat imagery in Hai Phong city, Vietnam. Paper presented at the International symposium on cartography in internet and ubiquitous environments.

Pohlert, T. (2017). Trend: non-parametric trend tests and changepoint detection. 2016. $R$ package version 0.2. 0 .

Rouse, J., Haas, R., Schell, J., \& Deering, D. (1974). Monitoring vegetation systems in the Great Plains with ERTS. NASA Special Publication, 351, 309.

Roy, D. P., Wulder, M., Loveland, T. R., Woodcock, C., Allen, R., Anderson, M., ... Kennedy, R. (2014). Landsat-8: Science and product vision for terrestrial global change research. Remote Sensing of Environment, 145, 154-172.

Son, N.-T., Chen, C.-F., Chang, N.-B., Chen, C.-R., Chang, L.-Y., \& Thanh, B.-X. (2014). Mangrove mapping and change detection in Ca Mau Peninsula, Vietnam, using Landsat data and object-based image analysis. IEEE Journal of Selected Topics in Applied Earth Observations, 8(2), 503510.

Stineman, R. W. (1980). A consistently well-behaved method of interpolation. Creative Computing.

Taddeo, S., Dronova, I., \& Depsky, N. (2019). Spectral vegetation indices of wetland greenness: Responses to vegetation structure, composition, and spatial distribution. Remote Sensing of Environment, 234, 111467.

Valiela, I., Bowen, J. L., \& York, J. K. (2001). Mangrove Forests: One of the World's Threatened Major Tropical Environments: At least 35\% of the area of mangrove forests has been lost in the past two decades, losses that exceed those for tropical rain forests and coral reefs, two other well-known threatened environments. Bioscience, 51(10), 807-815.

Weiss, D. J., Atkinson, P. M., Bhatt, S., Mappin, B., Hay, S. I., \& Gething, P. W. (2014). An effective approach for gapfilling continental scale remotely sensed time-series. ISPRS Journal of Photogrammetry and Remote Sensing, 98, 106-118.

Yuwono, E., Jennerjahn, T., Nordhaus, I., Riyanto, E. A., Sastranegara, M. H., \& Pribadi, R. (2007). Ecological status of Segara Anakan, Indonesia: a mangrove-fringed lagoon affected by human activities. Asian Journal of Water, Environment Pollution, 4(1), 61-70.

Zhang, Q., Shi, P., Singh, V. P., Fan, K., \& Huang, J. (2017). Spatial downscaling of TRMM-based precipitation data using vegetative response in Xinjiang, China. International Journal of Climatology, 37(10), 3895-3909.

Zhang, X., Jiang, H., Zhou, G., Xiao, Z., \& Zhang, Z. (2012). Geostatistical interpolation of missing data and downscaling of spatial resolution for remotely sensed atmospheric methane column concentrations. International Journal of Remote Sensing, 33(1), 120-134. 